\title{
Neglected Tropical Diseases: A Continuing Priority and a Lurking Threat
}

\author{
Henry Benerman 1
}

${ }^{1}$ Department of Electrical Engineering, Colorado State University, Fort Collins, CO 80523

\section{DISCUSSION:}

Deep within a military base, a group of people tensely, but calmly tend to a variety of tasks. Some organize law enforcement, others keep medical teams safe and supplied, and still others spent their time simply keeping a lengthy chain of command well informed. This is the worst scenario, any worst scenario; whether that be a disease outbreak, severe weather event, or nuclear detonation. These are the front lines of any wide-scale disaster. The U.S government has spent a considerable amount of time and resources attempting to prepare for any widescale disaster [1]. Many systems are in place to help alleviate the effects of catastrophe; and one of the benefits of living in a developed country is that people are able to access those systems in times of need. Unfortunately, many nations lack the proper infrastructure to properly handle severe outbreaks that periodically plague their populations, much less handle epidemics that occur on an annual or biannual basis. Compounding this issue is the fact that many of the world's most disfiguring diseases are considered "neglected" compared to illnesses endemic to first-world countries. The "neglected" classification stems from the historically low research efforts put towards curing or preventing these diseases. These diseases, known as Neglected Tropical Diseases or NTDs, affect over a billion people worldwide [2], and several show no sign of slowing down. Diseases like Malaria affect 990 million people and kill 2.7 million per year [3] with chances of re-infection later in life. Others are the cause of fewer deaths but often leave victims with grotesque deformities such as lymphatic filariasis, also known as elephantiasis, which afflicts more than 120 million people worldwide [2]. While there are numerous factors involved with the present status of NTDs, more must be done. Governments of western nations should make a concerted effort to fund more research projects involving NTDs. Both the risk to developed nations' populations and their interests is great enough to warrant investigations into making treatments that are affordable and ubiquitous.
NTDs may have different vectors and be endemic to different regions, but most have the same key identifiers in common. NTDs are easily communicable viruses, parasites, or bacteria that cause significant health impacts. They are also typically endemic to tropical regions [4]. NTDs are also characterized by their disproportionate impact on poverty stricken regions and populations [5]. Many countries, especially those found in South America, East Asia, and sub-Saharan Africa have civilian and military populations that are at risk of contracting these NTDs Additionally, a defining factor of NTDs are that research is mostly underfunded and/or lack any affordable treatments [6]. It is this third aspect that compounds all others by allowing millions of people to suffer despite the capacity to develop therapeutics capable of treating these illnesses. Across the board, there are many species that both carry and cause NTDs. Some common examples of NTDs include Chagas' disease, trypanosomiasis, and Hook worm. Chagas' disease is caused by the parasite Trypanosoma cruzi, an organism endemic to Central and South America. Chagas' disease is a chronic ailment that often causes cardiac arrest in patients who are in the later stages of the disease [7]. Like many diseases classified as NTDs, there are treatment and prevention options that exist, but most of those treatments are not affordable to many people living in the affected areas. It is because of this lack of support that more than 6 million people are affected by this category of diseases [7]. Another example, affecting primarily Central and Northern Africa is Trypanosomiasis, otherwise known as sleeping sickness. Sleeping sickness is caused by a protozoon known as T. brucei gambiense which is able to cross the blood brain barrier and cripple the central immune system causing death in the victim if not treated [3]. Again, this disease is an example of one that is treatable and rare in western countries, but remains an endemic disease in third world countries due to ineffective infrastructure [5]. In addition to the lack of preventative infrastructure and affordable treatment options, the lack of sanitary conditions and

This article is published under the terms of the Creative Commons Attribution License 4.0

Author(s) retain the copyright of this article. Publication rights with Alkhaer Publications.

Published at: http://www.ijsciences.com/pub/issue/2017-07/

DOI: 10.18483/ijSci.1311; Online ISSN: 2305-3925; Print ISSN: 2410-4477 
regional conflicts can exacerbate the impacts of NTDs. Poor living conditions can provide additional ways for the organisms to infect human populations and regional conflict can make outside support and resources difficult to receive. The reality of NTDs goes far beyond a simple bacterial or viral infection. Many nations struggle with NTDs because of many historical, sociopolitical, and environmental factors. But the ramifications of these seemingly exotic diseases can have far greater impacts than we realize.

The first major problem of NTDs that is often ignored is the security issues associated with them, especially within the context of the military. One of the more well-known facets of this is bioterrorism and war with militaries being at a particularly high risk [8]. Combatants engaged in region where these diseases are endemic can be susceptible to illnesses that can compromise their ability to fight. Relatively acute diseases such as cholera and malaria may be treatable within a reasonable time frame, but the severity of their symptoms can leave western militaries at tactical disadvantages. These impacts could pale in comparison to the impact of more chronic diseases. Many NTDs take years before any symptoms manifest. Illnesses like Chagas disease, sleeping sickness, and elephantiasis take months, sometimes years to become symptomatic [4][14]. While many of these more chronic diseases are not easily transmissible within the context of the United States or other Western nations. The sheer amount of time that can pass before these diseases become symptomatic can create risk of massive outbreaks. One current example of this is the effect of NTDs on African militaries. Many African militaries are facing rising HIV infections [8]. Culture in African militaries favors chauvinistic and reckless behavior, which in turn leads to HIV infections. This places a large burden on the governments of those nations to care for those soldiers while reducing the number of troops healthy enough to perform their duties. Infected soldiers can return from combat zones and spread the disease to segments of the population that would not have otherwise had an exceptional risk of exposure. The microcosm demonstrated by the militaries of African nations can be extended to western militaries as well. By studying these diseases in places where western countries hold interests, governments can better protect both their troops should conflicts arise and protect civilians representing those interests. This can also go both ways. By providing proactive support to the native populations, Western nations can help alleviate the risks to their citizens and improve relationships with countries where NTDs are endemic.

The other side to the neglected tropical disease security debate is the possibility of target NTDs infecting western civilian populations. Perhaps the better-known extension of this is bioterrorism. Many NTDs are known to be extremely communicable, and several would pose great risk if they were rendered endemic to western nations. Western nations, especially the United States, are vulnerable to several diseases as shown by a series of Anthrax simulant tests conducted by the United States' government throughout the 1960s [9]. Even though anthrax as a war pathogen has been researched and preparations have been made, it is illustrative of the scope of the more virulent neglected tropical diseases. Acute neglected tropical diseases like cholera could put millions at risk of death in a relatively short amount of time with risk of reinfection. More severe pathogens such as Ebola could also pose a great risk to western nations not simply with regard to their high mortality rate, but with the immense expenditure of resources that would accompany such an outbreak. NTDs could potentially become a severe issue within western nations at any time; and while outbreaks within developed nations would be handled more effectively than outbreaks in less developed nations, the effects of one outbreak would be resource intensive. The benefits of funding research of NTDs would have the dual effect of better preparing western populations for the strong possibility of a disease becoming endemic and proactively ending the diseases in their native environments, thus reducing the likelihood that one of these diseases can enter a western nation.

Unfortunately, NTD outbreaks in western nations have ceased to be mere possibilities in several incidents. They are not exclusively found in the tropical regions as their classification suggests. There are several instances where NTDs have crossed nation's borders to the West; even to the United States, the HIV/AIDS epidemic of the 1980s being one relevant historical example [6]. While HIV/AIDS does have a sizable presence in the United States, it is still considered "neglected' because of its high rate of transmission, disproportionate effect on developing countries, and costly treatment options. HIV/AIDS does have one advantage though: due to its impact on the United States, HIV/AIDS has received considerably more visibility, and thus research spending, than other NTDs. Beyond the politics associated with HIV and AIDS, some diseases can severely impact Americans' health without the same visibility of HIV/AIDS. The presences of people living with Chagas diseases being a prime example. Per a paper published by Dr. Caryn Burn, there are around 30,000 people infected with $T$. cruzi parasite living in the United States [10]. While her paper did not mention the proportion of the number of infected who are American citizens, the matter still becomes 
pressing when viewed from a practical standpoint. The number of people with Chagas' diseases is growing in the United States by about 315 infections in the United States per year [10]. Most of T. Cruzi infections come from immigrant populations with about 1.13 percent of immigrants from Mexico, Central, and South American affected [10]. Despite this predominance of $T$. Cruzi vectors in Latin American countries, the vector of the Chagas' disease parasite can be found as far north as Pennsylvania [11]. With more than half the United States endemic to the vector of Chagas' diseases, the United States has enough of a stake in finding a solution to warrant allocating more resources to the problem. Even though the risk of Chagas disease is low in the United State, it still affects U.S citizens. This, considering the millions of people in countries with U.S interests should serve as enough impetus for the United States government to fund more research into affordable Chagas' disease treatment.

While there are many reasons to bolster funding to developing effective and affordable treatments for NTDs, there are also some points to consider in analyzing the issue. One thing that came up while researching this article was a distinct lack of journal papers and articles that specifically held a position arguing against funding NTDs or even reducing current aid. While there are concrete reasons to reduce, or discontinue funding, there do not seem to be many people willing to get up on the pulpit, so to say. Perhaps the idea of allowing the continued suffering of millions of people worldwide by the way of treatable diseases is an unpopular prospect for most people. Fear of negatively impacting one's reputation to frame the social injustice of granting people lifesaving treatments for NTDs may be an underlying cause of the lack of inaction. In any case, the issue of funding NTDs remains to be solved completely, even if advances have been made. If the primary goal of a government is to protect and serve its citizens, then the question remains whether they have any reason to stretch already shrinking budgets to protect populations largely irrelevant to them. However, suffering or not, there are real reasons to not spent money and resources on NTD research.

One of the major problems that comes in funding research that impacts few American citizens is the pure economics of the enterprise. In most cases, there is little or no chance that the companies developing these drugs would make a reasonable return on their investments [12]. This is mostly due to the large population of people that would use or need these treatments would also be unable to pay for them. This would drain a company's financial resources and be considered a poor investment by most standards. The burden would then fall to taxpayers to allocate funding to research. However, it would be a difficult sell to allocate more taxpayer dollars to researching diseases which have little practical effects on them. A parallel example of this rests in the similar realm of orphan diseases. Orphan diseases are diseases that affect a very small population within almost any population. These include rare cancers and congenital disorders as well as chronic disorders like prion disorders with extremely low transmission rates such as Creutzfeldt-Jakob disease. Insurance companies, as expected, have few plans for insuring people afflicted with these Orphan diseases [13]. Most people who have these diseases are forced to spend thousands of dollars per year for treatments and medications. Insurance companies simply do not want to cover the costs of treatments that affect few and have little chance of returning their investment. Despite these counter arguments, there are still an abundance of reasons that NTD research should be funded despite the obstacles brought on by capitalism.

Even if funding treatments for these diseases is not economically sound, there are several points that should be taken into consideration. Perhaps one major pitfall that could arise is the direct result of a living in a capitalistic system. If a neglected tropical disease outbreak occurs in a western nation, a conflict of interest may arise. If an outbreak occurs, and a large proportion of the U.S. population requires treatments, these companies would be suddenly incentivized to fund development. While this in theory is not a terrible problem, it may lead to a worst-case scenario where pharmaceutical companies lobby against governments funding neglected tropical diseases. The major issue would be that many lives would be lost as companies turn a profit. Therefore, governments must take a greater role of responsibility in funding NTD research. The best way for governments take this responsibility is to incentivize pharmaceutical companies to both develop and manufacture low-cost treatments for NTDs. This will enable the current capitalistic structure to drive the creation of systems that will protect lives in developed and underdeveloped countries.

It is as important to consider the ramifications on outside parties as it is to consider the ramifications to themselves. This ethical consideration also applies to neglected tropical diseases. Most instances of widespread NTDs are the direct result of extreme differences in circumstance [6]. Even though NTDs affect western nations, the infrastructure already in place helps greatly alleviate any sized outbreak. Developing countries' lack of resources complicate even mild outbreaks. NTDs have a disproportionate 
effect on those who are at the most risk. Even from a purely utilitarian point of view, western nations have an ethical obligation to at least support developing countries in their efforts to maintain the health of their citizens. Human rights have been argued of late in a social and cultural context as well as a political context. The process by which scientists must think about global ethics is evolving. The world is no longer as segmented as it once was. The ripples of an outbreak have visible repercussions on the west. Whether it is as simple as a business experiencing the loss of financial assets in West Africa or a small outbreak in a western nation. There are always consequences to not acting. This enlightened age ensures we must see it.

Neglected tropical diseases are an unfortunate fact of society. The organisms that cause them have coexisted alongside human kind since Homo sapiens first began evolving. In this hyper-connected age of science and research, it is an ethical and practical travesty to allow these organisms to infect populations of developing nations when the infrastructure exists to research treatments. These diseases have potential to become problems for western nations as an outbreak or as a lost economic opportunity. Civilization is entering a period unlike any in history before it. Thus, it is imperative that all nations, developing, developed, or otherwise, must look out for one another. Governments need to incentivize research of NTDs even if they do not provide direct funding themselves. The victims of NTDs number in the hundreds of millions, resulting in needless losses of a resource that is becoming ever important to maintain. However, with the proper funding and support, many of these countries will eventually acquire the resources and infrastructure to vastly reduce the occurrence of outbreaks from a yearly outbreak into a rarity. Something that a few highly trained and experienced personnel worry over from deep inside a military base.

\section{References}

1) Agency FEMA. About the Agency www.fema.gov 2016 [updated April 1, 2016; cited 2016 April 6, 2016]. Available from: https://www.fema.gov/about-agency.

2) Salaam-Blyther T. Neglected Tropical Diseases: Background, Responses, and Issues for Congress. In: Service CR, editor. 2011.

3) Aldridge S. Tropical Infectious Diseases. In: Lerner BW, Lerner KL, editors. Infectious Diseases: In Context: Gale 2008. p. 834-6.

4) Malaria GH-DoPDa. Neglected Tropical Diseases. Which diseases are considered Neglected Tropical Diseases? Centers for Disease Control and Prevention: Department of Health and Human Services; 2011.

5) Oprea L, Braunack-Mayer A, Gericke CA. Ethical issues in funding research and development of drugs for neglected tropical diseases. Journal of Medical Ethics: BMJ Publishing Group; 2009. p. 310-4.

6) Trouiller P, Olliaro P, Torreele E, Orbinski J, Liang R, Ford N. Drug Development of neglected diseases. a deficient market and a public-health policy failure. The Lancet: Elsevier Inc.; 2002. p. 2188-94

7) Organization WH. Chagas disease (American trypanosomiasis) Fact Sheet. World Health Organization2016.

8) Albon CR. Infectious Diseases Threaten National Security. Do Infectious Diseases Pose a Threat? Current Intelligence: Greenhaven Press; 2014.

9) Frischknecht F. The history of biological warfare. EMBO Reports: The European Molecular Biology Organization; 2003. p. S47-S52.

10) Burn C, Montgomery SP. An Estimate of the Burden of Chagas Disease in the United States. Clinical Infectious Diseases: Oxford Journals; 2009.

11) Control CfD. Parasites-American Trypanosomiasis (also known as Chagas Disease). Triatomine Bug FAQs: United States Department of Health and Human Services; 2016.

12) Barder O, Kremer M, Williams H. Advance Market Commitments. A Policy to Stimulate Investment in Vaccines for Neglected Diseases. Economists' Voice: The Berkeley Electronic Press; 2006. p. 1-6.

13) Handfield R, Feldstein J. Insurance Companies' Perspectives on the Orphan Drug Pipeline. American Health \& Drug Benefits2013. p. 589-97.

14) Newton-Sanchez, O. A. Seroprevalence of Trypanosoma cruzi (TC) and risk factors in Colima, Mexico. Gaceta Medica de Mexico S; 2013. p.0016-3813. 